\title{
Title: Dual-Task Effect on Cognitive and Body Function, $\beta$ - amyloid Levels in Alzheimer's Dementia Patients: a Randomized Controlled Trial
}

Author 1: Seung Min Nam, PhD, PT

1) Department of Physical Therapy, Daegu University

2) Mailing Address: 201, Daegudae-ro, Jillyang-eup, Gyeongsan-si, Gyeongsangbuk-do, Republic of Korea

3) Tel: 82-53-850-4350, 4) FAX: 82-53-850-4359, 5) e-mail: ngd1339@naver.com

Author 2: Seong Gil Kim, Prof, PhD, PT (Corresponding author)

1) Professor, Department of Physical Therapy, Sun Moon University

2) Mailing Address: 70, Sunmoon-ro 221beon-gil, Tangjeong-myeon, Asan-si, Chungcheongnam-do, Republic of Korea

3) Tel: 82-41-530-2739, 4) FAX: 82-504-442-4129, 5) e-mail: niceguygil@gmail.com 


\title{
Title: Dual-Task Effect on Cognitive and Body Function, $\beta$ - amyloid Levels in Alzheimer's Dementia Patients: a Randomized Controlled Trial
}

\begin{abstract}
The purpose of this study is to explore the effects of dual-task training, including cognitive tasks, on cognitive and bodily functioning and $\beta$-amyloid levels in Alzheimer's dementia patients. The subjects were 34 inpatients diagnosed with Alzheimer's dementia at a nursing hospital located in Gyeongsansi, South Korea. The patients were randomly divided into a dual-task group $(n=16)$ and a single-task group $(n=18)$. The dual-task group performed cognitive tasks at the same time as exercising tasks, while the single-task group performed only exercise tasks. Each group was trained for 30 minutes three times a week for eight weeks. The Mini-Mental State Examination was used to measure the patients' cognitive function. Static and dynamic balance were measured to evaluate bodily functioning. Static balance was measured using Biorescue, while dynamic balance was measured using the Berg Balance Scale. Blood analysis was performed to measure levels of $\beta$-amyloid, which is known to cause Alzheimer's dementia. Both groups exhibited statistically significant improvements in gait function after the training $(\mathrm{p}<.05)$. The dual-task group exhibited statistically significant differences in cognitive function, static and dynamic balance function, and $\beta$-amyloid levels after training $(\mathrm{p}<.05)$. A significant difference was observed between the two groups $(p<.05)$. Dual-task activities were found to be effective in improving cognitive and bodily functioning and reducing $\beta$-amyloid levels in Alzheimer's dementia patients. Therefore, dual-task training is thought to be an effective method of treating and preventing Alzheimer's dementia.
\end{abstract}

Keywords: Alzheimer's Disease, Task Performance, Cognition, Human Activities, Amyloid Beta Protein, Dementia 


\section{Introduction}

Dementia is a comprehensive condition in which various levels of cognitive function are impaired due to brain damage caused by various factors. It disrupts the activities of daily living of patients. Dementia causes mature brains to become damaged or destroyed by trauma and disease, leading to cognitive and behavioral disorders. It is a complex clinical syndrome that disrupts patients' daily lives [1]. Dementia is a typical geriatric chronic disease, the prevalence of which increases about twice as much as the age of four increases. The number of dementia patients increases in proportion to increases in the elderly population [2].

The most common type of dementia is Alzheimer's dementia. This degenerative brain disease accounts for $70.7 \%$ of dementia. Alzheimer's dementia causes a protein called $\beta$ amyloid to settle in the brain and form plaque. This protein is toxic to brain cells. It causes gradual necrosis of brain cells, resulting in disruptions in signal transmission and atrophy and failure of the brain [3, 4]. Alzheimer's dementia is irreversible and incurable. However, early diagnosis and treatment can slow its progress and improve symptoms [5].

In general, Alzheimer's dementia is clinically defined as symptomatic, with clinical symptoms classified into two types: cognitive and physical. First, a decline in cognitive function occurs, which generally manifests as partial disability in functions such as intelligence, memory, attention, language ability, execution ability, and space-time classification $[6,7]$. Second is a deterioration in physical functioning. In dementia patients, physical activity decreases gradually due to decreased cognitive function, which leads to reduced physical functioning and impaired performance of daily life tasks [8,9]. In particular, as degenerative body changes such as muscular atrophy, bone loss, and joint deformation increase and vestibular organ function decreases, elderly patients with dementia find that their walking speed and balance ability are reduced [10]. This results in bodily instability, which increases the risk of falls and fractures [11].

The main therapy for Alzheimer's dementia is medication. However, a recent study showed that cognitive rehabilitation and exercise therapy also improved cognitive function and the performance of daily life activities in patients with Alzheimer's dementia [12]. A metaanalysis showed that dual-task training is an effective non-pharmaceutical treatment for Alzheimer's dementia [13]. According to another recent study, dual-task exercises are shown to be more effective than single-task training for Alzheimer's dementia patients [14]. Dualtask performance refers to the performance of two tasks at the same time. Dual tasks require cognitive effort and concentration and are reported to improve brain function and cognitive 
function [15]. Since balance and bodily stability are required in situations involving secondary task performance, dual-task training is particularly valuable for Alzheimer's dementia patients with both motor and cognitive impairment [16]. Prior studies have shown that physical and cognitive dual-task training led to improvements in cognitive function, balance and gait function, and performance of daily life activities in normal older people, stroke patients, and other neurological patients [17, 18].

In general, dual-task training can be divided into training in performing two exercises at the same time and training in the performance of a motor task and a cognitive task at the same time. For elderly dementia patients, dual-task training should involve cognitive tasks related to cognitive improvement [19]. Dual-task training is effective in promoting cognitive and physical functioning in patients with neurological disorders related to motor learning and older people [20]. However, research on effective early prevention and exercise methods for Alzheimer's dementia patients is needed. There is a lack of research on the effectiveness of dual-task training for Alzheimer's dementia patients. The purpose of this study is to explore the effects of dual-task training, including cognitive tasks, on cognitive and bodily functioning and $\beta$-amyloid levels in Alzheimer's dementia patients.

\section{Methods}

Subjects

The study was conducted on 34 elderly patients diagnosed with Alzheimer's dementia at S Nursing Hospital in Gyeongsansi. The purpose of the study and the details of the experiment were explained to the subjects, and their voluntary consent to participate was obtained. This research was approved by the Daegu University Bioethics Committee (1040621-201711HRBR-004-002). The G*Power 3.1.9.6 program was used to determine the appropriate number of subjects. Based on the power analysis presented by Cohen, it was estimated that 21 subjects were required for each group at an effect size of 0.8 , a significance level of 0.05 , and a statistical power of $70 \%$. However, 45 people were selected in anticipation of dropouts. The final number of patients studied was 34. The criteria for selection and exclusion of subjects were as follows. The criteria for selection were Mini-Mental State Examination (MMSE) scores of 18-23; Global Detration Scale scores of 4-5; stand or gait independently; and those who participated in other exercise programs. 


\section{Study Protocol}

Dual-task training that includes a cognitive task should involve the performance of both tasks at the same time, and exercises should be as simple as possible to ensure selective attention when performing cognitive tasks. Dual-task training for Alzheimer's dementia patients has included aerobic, balance, and muscle-strengthening exercises together with cognitive training using numbers, words, and pictures [19-21]. According to the motor learning stage, both the dual-task training group and the single-task training group carried out only motor tasks for the first two weeks of training. From the third week of training, the dualtask training group carried out additional cognitive tasks during the exercise. The training was conducted for 30 minutes three times a week for eight weeks, depending on the training methods of each group. During the training, patients were allowed to rest if they experienced discomfort, fatigue, or pain (Table 1). 
Table 1.

Dual task training methods

\begin{tabular}{|c|c|c|}
\hline & Exercise & Additional Cognitive Task \\
\hline & Standing up on the bed & \\
\hline & (5 minutes) & (1) counting numbers without sound \\
\hline & In a standing posture & Ex) $100,99,98,97 \ldots$ \\
\hline & Stretch your arms in many directions & (2) simple arithmetic \\
\hline & (5 minutes) & Ex) $2+3,9-4$ \\
\hline Dual task & In a standing posture & (3) word association \\
\hline training & Lifting the heeld & Say a word starting with a consonant \\
\hline$(30$ minutes) & (5 minutes) & (4) matching the proposed picture \\
\hline & One foot on the wall & Ex) things, places, animals, etc. \\
\hline & Alternating tolerance & (5) pictures, letters, objects, etc. presented; \\
\hline & (5 minutes) & Remember and answer \\
\hline & Walking on flat & \\
\hline & $\begin{array}{l}\text { (5 minutes) } \\
\text { wheeling }\end{array}$ & $\begin{array}{l}\text { Therapist randomly selects five cognitive } \\
\text { tasks. Present along with the exercise }\end{array}$ \\
\hline & (5 minutes) & \\
\hline
\end{tabular}

\section{Mini-Mental State Examination (MMSE)}

The Mini-Mental State Examination (MMSE), a tool developed in the United States, is currently the most widely used screening tool for dementia. It has the advantage of facilitating easy evaluation of the intellectual status and cognitive function of the examinee in a short time. The MMSE-K consists of 12 questions and a total score of 30 points: 5 points for time orientation, 5 points for place orientation, 3 points for memory registration, 5 points for attention and calculation, and 9 points for comprehension and language skills. A score of 24 points or higher is classified as normal cognitive function, while 18-23 points indicates 
mild dementia, and 17 points or less indicates moderate or severe dementia.

\section{Biorescue}

The Biorescue biofeedback analysis system (Biorescue, France) is a device that measures balance ability. It has been used on various subjects, including patients, the general public, and athletes. It measures length $(\mathrm{mm})$ and average speed $(\mathrm{cm} / \mathrm{s})$. In order to evaluate the static balance ability, the limit of stability in the standing posture was measured. For the eight directions indicated on the monitor, the total distance and area of the center of gravity were measured for the weight movements forward, back, left, and right. The monitor displayed an explanation of the measurement method and a demonstration of the test. The subject held one leg forward at $30^{\circ}$ in a forward-looking standing position and then used an ankle joint strategy to achieve maximum range without losing balance. The limit of their ability to move from their center of gravity was measured.

Berg Balance Scale (BBS)

Berg Balance Scale (BBS) can objectively assess fall risk, static balance ability, and dynamic balance ability in elderly subjects by measuring the functional balance performance during sitting, standing, and posture changes. The scale is composed of 14 items, and if the task cannot be performed, the total score is 56, a maximum of 4 points being applied to each item if it is independently performed. In general, the higher the score, the better the subject's balance ability. A score of 0-20 points indicates balance disorder, while a score of 41-56 points indicates good balance.

\section{0-Meter Walk Test (10MWT)}

10-meter walk test (10MWT) evaluates walking ability by measuring the walking speed of the examinee. No special equipment is required, which means that walking ability can be evaluated easily in a short time. The test measures the time required to walk a distance of 10 $\mathrm{m}$, taking into account acceleration and deceleration between the start- and endpoints. The test is performed three times to obtain an average measurement.

Blood Analysis

Blood analysis was performed to measure $\beta$-amyloid levels. $\beta$-amyloid is a protein that settles in various areas of the brain, causing dementia. After 12 hours of fasting, a disposable syringe was inserted into the anterior vein to collect $10 \mathrm{ml}$ of blood before and after 8 weeks 
of training. The collected blood was stored at room temperature for at least 30 minutes, and centrifugation was performed at $3000 \mathrm{rpm}$ for 10 minutes. The separated serum was then frozen at $-20^{\circ} \mathrm{C}$ or below for analysis. The analysis was performed using the Infinite M200Pro ELISA Reader (TECAN, Austria) and the enzyme immunoassay (EIA) method.

Statistical Analysis

The Shapiro-Wilk test was performed to check for the normal distribution of each measurement item, and the results for all items satisfied normality. The data were presented as mean \pm standard deviation (Mean $\pm \mathrm{SD}$ ), and the general characteristics of the subjects were presented as descriptive statistics. A paired t-test was performed to compare pre- and post-training performance within the dual- and single-task groups. An independent t-test was performed for between-group comparisons. The data collected for this study was statistically processed using SPSS 22.0 for Windows (IBM, New York, USA) and the statistical significance level (p) was set to.05

\section{Results}

A homogeneity test showed no statistical difference between the groups $(\mathrm{p}>.05)$ (Table 2$)$. The results of the 10MWT showed a significant decrease after training in both the dual-task group and the single-task group $(\mathrm{p}<.05)$, with no significant difference between the groups $(p>.05)$. The results of the MMSE-K, LOS, BBS, and $\beta$-amyloid level test showed significant differences after training in the dual-task group $(\mathrm{p}<.05)$ but not in the single-task group $(\mathrm{p}>.05)$. In these four tests, significant differences were observed between the groups $(\mathrm{p}<.05)$ (Table 3). 
Table 2.

General characteristics of subjects

\begin{tabular}{llll}
\hline & DTG(n=16) & STG $(\mathrm{n}=18)$ & $\mathrm{p}$ \\
\hline Gender (M/F) & $4 / 12$ & $3 / 15$ & .640 \\
Age(year) & $78.41 \pm 8.51$ & $79.61 \pm 7.45$ & .886 \\
Height(cm) & $155.82 \pm 11.25$ & $153.33 \pm 8.99$ & .607 \\
Weight(kg) & $54.33 \pm 12.25$ & $46.22 \pm 11.71$ & .109 \\
\hline
\end{tabular}

Mean \pm SD : mean \pm standard deviation

DTG; Dual Task Group, STG; Single Task Group

*p<.05

Table 3.

Comparison of Cognitive and Body Function, $\beta$-amyloid for each group

\begin{tabular}{|c|c|c|c|c|}
\hline & & DTG(n=16) & $\operatorname{STG}(\mathrm{n}=18)$ & $\mathrm{p}$ \\
\hline \multirow{4}{*}{ MMSE(score) } & Pre & $20.43 \pm 1.76$ & $20.11 \pm 2.21$ & .511 \\
\hline & Post & $21.73 \pm 1.79$ & $20.22 \pm 2.26$ & $.034^{*}$ \\
\hline & $\mathrm{p}$ & $.000^{*}$ & .631 & \\
\hline & Pre & $370.02 \pm 180.46$ & $387.63 \pm 80.11$ & .708 \\
\hline \multirow[t]{3}{*}{$\operatorname{LOSL}(\mathrm{mm})$} & Post & $539.28 \pm 204.73$ & $418.09 \pm 113.85$ & $.035^{*}$ \\
\hline & $\mathrm{p}$ & $.000^{*}$ & .337 & \\
\hline & Pre & $428.89 \pm 169.06$ & $436.39 \pm 87.25$ & .868 \\
\hline \multirow[t]{3}{*}{$\operatorname{LOSR}(\mathrm{mm})$} & Post & $593.72 \pm 188.98$ & $441.30 \pm 121.56$ & $.007^{*}$ \\
\hline & $\mathrm{p}$ & $.000^{*}$ & .862 & \\
\hline & Pre & $691.17 \pm 176.04$ & $668.81 \pm 119.71$ & .659 \\
\hline \multirow[t]{2}{*}{$\operatorname{LOSF}(\mathrm{mm})$} & Post & $824.36 \pm 168.77$ & $683.25 \pm 125.81$ & $.007^{*}$ \\
\hline & $\mathrm{p}$ & $.000^{*}$ & .427 & \\
\hline $\operatorname{LOSB}(\mathrm{mm})$ & Pre & $274.43 \pm 122.53$ & $261.39 \pm 77.28$ & .771 \\
\hline
\end{tabular}




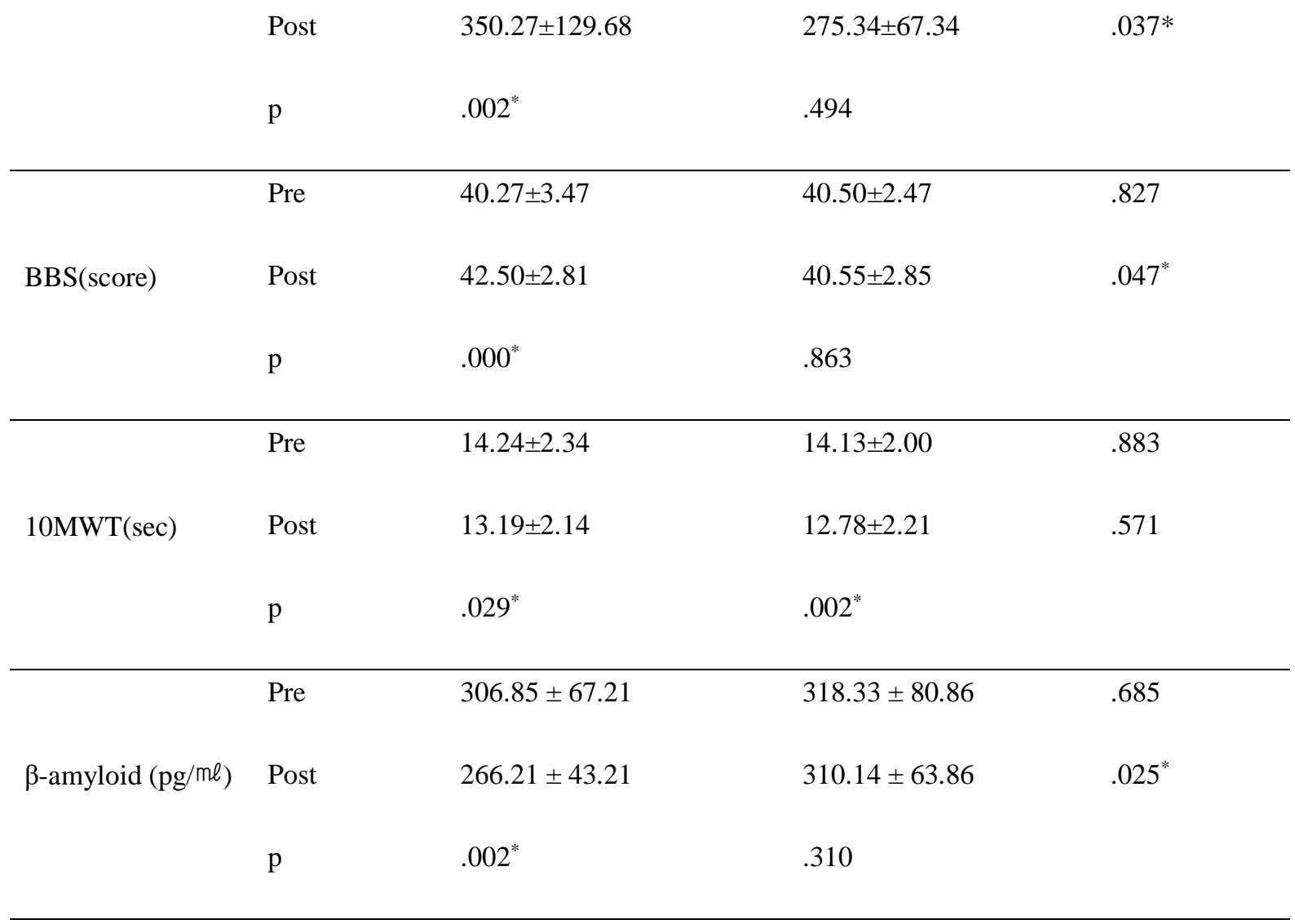

Mean \pm SD : mean \pm standard deviation

DTG; Dual Task Group, STG; Single Task Group, MMSE; Mini Mental State Examination, LOSL; Limit of Stability Left, LOSR; Limit of Stability Right, LOSF; Limit of Stability Forward, LOSB; Limit of Stability Back, BBS; Berg Balance Scale, 10MWT;10-Meter Walk Test " $\mathrm{p}<.05$

\section{Discussion}

The purpose of investigating the effects of dual-task training on patients with Alzheimer's dementia was to obtain basic data for the early prevention of the disease. To examine the effects of training on cognitive and body function, $\beta$-amyloid levels were evaluated. Bodily functioning was evaluated by testing static balance ability, dynamic balance ability, and gait function.

The MMSE scores increased significantly after training in the dual-task group, but no significant difference was observed after training in the single-task group. There was a significant difference between the groups after training. These results are consistent with a prior study that improved MMSE scores in elderly subjects after dual-task training including cognitive tasks [22]. Furthermore, prior studies have shown that dual-task training improved overall cognitive functioning in elderly subjects with mild cognitive impairment. Dual-task 
training has also been reported to have improved cognitive function in $80 \%$ of the elderly who have fallen $[23,24]$. Alzheimer's dementia causes degenerative changes in various areas of the cerebral epidermis as it progresses, resulting in a decline in various cognitive functions. While a single task only activates a small number of brain functions, dual-task activities, which involve the performance of two tasks simultaneously, require cognitive, practical, and focused skills. Such activities are effective in improving cognitive function in Alzheimer's dementia patients. Dual-task training is particularly effective in practicing the cognitive skills required to coordinate various tasks. These skills are necessary to perform the complex and diverse tasks that people are required to perform in their daily lives [25, 26].

To evaluate changes in static balance and dynamic balance ability, a limit of stability test and the BBS were performed. The limit of stability and Berg balance scores increased significantly in the dual-task group after training, but no significant difference was observed in the single-task group. There was a significant difference between the two groups after training. These findings are consistent with those of previous studies, which found that dualtask performance reduced postural fluctuations and improved postural stability in stroke patients and normal subjects [25]. They are also consistent with reports of significant improvements in dynamic balance in normal older people and older people with mild cognitive impairment as a result of dual-task training [27]. The addition of cognitive task training to a single motor task is thought to reduce postural disturbance and improve postural stability by reducing the level of conscious concentration that occurs when maintaining balance, thereby reducing the effect of concentration on the upper center in postural control when switching to task performance.

The results of the 10MWT were significantly lower after training in both the dual-task and single-task groups, and no significant difference between the groups was observed after training. These results are consistent with those of a study that showed a significant improvement in gait function in Alzheimer's dementia patients after dual-task training [28]. The results of the combined exercise program consisting of aerobic exercise and resistance exercise in patients with dementia were in good agreement with the results of the study, which showed a significant improvement in gait function [29]. In addition, a meta-analysis of the effects of exercise on cognitive impairment in dementia patients showed significant effects on gait speed and walking endurance [30]. It is thought that active exercise improves gait function by improving lower extremity muscle strength in patients with Alzheimer's 
dementia. In the present study, both groups performed gait training, and both showed significant improvements in gait function.

The dual-task group showed significantly reduced $\beta$-amyloid levels after training, while no significant difference was observed in the single-task group. A significant difference in $\beta$ amyloid levels was observed between the dual-task group and the single-task group after training. These results are consistent with those of prior research, which found dual-task activities to be effective in reducing $\beta$-amyloid levels in normal elderly people compared to single-task training and aerobic exercises [31]. Prior research has also shown that dual-task activities increase the intensity of brain waves responsible for attention and memory in elderly people with mild cognitive impairment, which improves overall cognitive function [32]. It has been reported that such activities improve synaptic plasticity, increase blood flow to the brain, accelerate the decomposition of $\beta$-amyloid, and activate a wider area of the brain [33]. The results of this study also showed a decrease in $\beta$-amyloid levels in Alzheimer's dementia patients after dual-task training, which is thought to have led to an improvement in overall cognitive function. Dual-task performance is an effective exercise method in reducing the risk factors for Alzheimer's dementia.

This study has certain limitations. First, the research was conducted on Alzheimer's dementia patients, so the results cannot be applied to all dementia patients. Further studies are required to distinguish between the types and severity of dementia. Second, the dual-task period was short. Further research is needed to investigate changes in the performance of daily life tasks as a result of long-term continuous dual-task training.

\section{Conclusion}

In sum, the results of this study confirm that dual-task training is effective in improving cognitive and bodily functioning and reducing $\beta$-amyloid levels in Alzheimer's dementia patients 


\section{REFERENCES}

1. Livingston, G.; Sommerlad, A.; Orgeta, V.; Costafreda, S. G.; Huntley, J.; Ames D. Dementia prevention, intervention, and care. The Lancet. 2017, 390, 2673-2734. [CrossRef]

2. Ritchie, K.; Lovestone, S. The dementias. The Lancet. 2002, 360, 1759-1766. [CrossRef]

3. Borroni, B.; Colciaghi, F.; Archetti, S.; Marcello, E.; Caimi, L.; Di Luca, M. Predicting cognitive decline in Alzheimer disease: Role of platelet amyloid precursor protein. Alz Dis Assoc Dis. 2004, 18, 32-34. [CrossRef]

4. Pietrzik, C.; Behl, C. Concepts for the treatment of Alzheimer's disease: molecular mechanisms and clinical application. Int J Exp Pathol. 2005, 86, 173-185. [CrossRef]

5. Thomas, V. S.; Hageman, P. A. A preliminary study on the reliability of physical performance measures in older day-care center clients with dementia. Int Psychoger. 2002, 14, 17-23. [CrossRef]

6. McAllister, T. W. Cognitive functioning in the affective disorders. Compr Psychiat. 1981, 22, 572586. [CrossRef]

7. Fratiglioni, L.; Launer, L. J.; Andersen, K.; Breteler, M. M.; Copeland, J. R.; Dartigues, J. F. Incidence of dementia and major subtypes in Europe: A collaborative study of population-based cohorts. Neurologic Diseases in the Elderly Research Group. Neurology. 2000, 54, 10-15. [CrossRef]

8. Teri, L.; McCurry, S. M.; Buchner, D. M.; Logsdon, R. G.; La Croix, A. Z.; Kukull, W. A. Exercise and activity level in Alzheimer's disease: a potential treatment focus. J Rehabil Res Dev. 1998, 35, 411. [CrossRef]

9. Feldman, H.; Sauter, A.; Donald, A.; Gélinas, I.; Gauthier, S.; Torfs, K. The disability assessment for dementia scale: a 12-month study of functional ability in mild to moderate severity Alzheimer disease. Alz Dis Assos Dis. 2001, 15, 89-95. [CrossRef]

10. Porter, M. M.; Vandervoort, A. A.; Lexell, J. Aging of human muscle: structure, function and adaptability. Scand J Med Sci Sports. 1995, 5, 129-142. [CrossRef]

11. Miller, P. A.; Butin, D. The role of occupational therapy in dementia-COPE (Caregiver Options for Practical Experiences). Int J Geriatr Psychiatry. 2000, 15, 86-89. [CrossRef]

12. Olazarán, J.; Reisberg, B.; Clare, L.; Peña-Casanova, J.; Del Ser, T.; Spector, A. Nonpharmacological therapies in Alzheimer's disease: a systematic review of efficacy. Dement Geriatr Cogn Disord. 2010, 30, 161-178. [CrossRef]

13. Verhaeghen, P.; Steitz, D. W.; Sliwinski, M. J.; Cerella, J. Aging and dual-task performance: a meta-analysis. Psychol Aging. 2003, 18, 443. [CrossRef]

14. Holtzer, R.; Mahoney, J. R.; Izzetoglu, M.; Izzetoglu, K.; Onaral, B.; Verghese, J. fNIRS study of walking and walking while talking in young and old individuals. J Gerontol A Biol Sci Med Sci. 2001, 66, 879-887. [CrossRef]

15. Woollacott, M.; Shumway-Cook, A. Attention and the control of posture and gait: a review of an emerging area of research. Gait Posture. 2002, 16, 1-14. [CrossRef]

16. McCulloch, K. L.; Mercer, V.; Giuliani, C.; Marshall, S. Development of a Clinical Measure of Dual 
task Performance in Walking: Reliability and Preliminary Validity of the Walking and Remembering Test. J Geriatr Phys Ther. 2009, 32, 2-9. [CrossRef]

17. Yang, Y. R.; Chen, Y. C.; Lee, C. S.; Cheng, S. J.; Wang, R. Y. Dual-task-related gait changes in individuals with stroke. Gait Posture. 2007, 25, 185-190. [CrossRef]

18. O'Shea, S.; Morris, M. E.; lansek, R. Dual task interference during gait in people with Parkinson disease: effects of motor versus cognitive secondary tasks. Phys Ther. 2002, 82, 888-897. [CrossRef]

19. Dennis, A.; Dawes, H.; Elsworth, C.; Collett, J.; Howells, K.; Wade, D. T. Fast walking under cognitive-motor interference conditions in chronic stroke. Brain Res. 2009, 1287, 104-110. [CrossRef]

20. Dean, C. M.; Richards, C. L.; Malouin F. Task-related circuit training improves performance of locomotor tasks in chronic stroke: a randomized, controlled pilot trial. Arch Phys Med Rehabil. 2000, 81, 409-417. [CrossRef]

21. Hollman, J. H.; Kovash, F. M.; Kubik, J. J.; Linbo, R. A. Age-related differences in spatiotemporal markers of gait stability during dual task walking. Gait Posture. 2007, 26, 113-119. [CrossRef]

22. Park, K. S.; Jeong, H. Y.; So, S. Y.; Park, Y. H.; Yang, H. J.; Jung, K. R.; The effects of the activity program for preventing dementia against depression, cognitive function, and quality of life for the elderly. JON. 2013, 24, 353-362. [CrossRef]

23. Kim, K.; Kim O. The effects of exercise-cognitive combined dual-task program on cognitive function and depression in elderly with mild cognitive impairment. Korean J Adult Nurs. 2015, 27: 707-717. [CrossRef]

24. You, J. H.; Shetty, A.; Jones, T.; Shields, K.; Belay, Y.; Brown D. Effects of dual-task cognitive-gait intervention on memory and gait dynamics in older adults with a history of falls: a preliminary investigation. NeuroRehab. 2009, 24, 193-198. [CrossRef]

25. Silsupadol, P.; Siu, K. C.; Shumway-Cook, A.; Woollacott, M. H. Training of balance under singleand dual-task conditions in older adults with balance impairment. Phys Ther. 2006, 86, 269-281. [CrossRef]

26. Michel, J. A., Mateer, C. A. Attention rehabilitation following stroke and traumatic brain injury: a review. Eur J Phys Rehabil Med. 2006, 42, 59. [CrossRef]

27. Pellecchia, G. L. Dual-task training reduces impact of cognitive task on postural sway. J Mot Behav. 2005, 37, 239-246. [CrossRef]

28. Montero-Odasso, M. M.; Sarquis-Adamson, Y.; Speechley, M.; Borrie, M. J.; Hachinski, V. C.; Wells, J. Association of dual-task gait with incident dementia in mild cognitive impairment: results from the gait and brain study. JAMA Neurol. 2017, 74, 857-865. [CrossRef]

29. Kemoun, G.; Thibaud, M.; Roumagne, N.; Carette, P.; Albinet, C.; Toussaint, L. Effects of a physical training programme on cognitive function and walking efficiency in elderly persons with dementia. Dement Geriatr Cogn Disord. 2010, 29, 109-114. [CrossRef]

30. Heyn, P.; Abreu, B. C.; Ottenbacher, K. J. The effects of exercise training on elderly persons with 
cognitive impairment and dementia: A meta-analysis. Arch Phys Med Rehabil. 2004, 85, 1694-1704. [CrossRef]

31. Yokoyama, H.; Okazaki, K.; Imai, D.; Yamashina, Y.; Takeda, R.; Naghavi, N. The effect of cognitive-motor dual-task training on cognitive function and plasma amyloid $\beta$ peptide 42/40 ratio in healthy elderly persons: a randomized controlled trial. BMC Geriatr. 2015, 15, 60. [CrossRef]

32. Hwang, J. H.; Park, M. S. Effect of a Dual-task Virtual Reality Program for Seniors with Mild Cognitive Impairment. Korean J Clin Lab Sci. 2018, 50, 492-500. [CrossRef]

33. Erickson, K. I.; Colcombe, S. J.; Wadhwa, R.; Bherer, L.; Peterson, M. S.; Scalf, P. E. Traininginduced functional activation changes in dual-task processing: an FMRI study. Cereb Cortex. 2006, 17, 192-204. [CrossRef] 